\title{
Isolation and Characterization of the Indigenous Acetic Acid Bacteria from Western Ghats Soil Samples
}

\author{
Anurag Bellankimath, Ajay Katti, V.B. Hemalata* and Bharati S. Meti* \\ Department of Biotechnology, Basaveshwar Engineering College, Bagalkot, Karnataka, India \\ *Corresponding author
}

\section{Keywords \\ Acetobacter, \\ Isolation, Soil, \\ Western Ghats, GYC.}

\section{Article Info}

Accepted:

17 July 2017

Available Online:

10 September 2017

\section{A B S T R A C T}

Acetic acid bacteria (AAB) are industrially important microorganism which is used in the production of alcohol and acetic acid. The study is carried out to Isolate and Characterise the bacteria isolated form different types of soil samples obtained from Western Ghats region. Various soil samples were collected from the Western Ghats of Belgaum and Khanapur region. These samples were screened for the presence of the acetic acid bacteria on the GYC media (glucose, yeast extract and calcium carbonate). The positive isolates were further grown in Carr medium supplemented with bromocresol blue to differentiate between the acetobacter and gluconobacter species. The biochemical tests were performed for characterization followed by 16s rRNA and the restriction analysis of the isolates. Out of the total twenty isolates of the acetobacter and gluconobacter, two acetobacter isolates were considered for 16s rRNA analysis based on the colony morphology and biochemical characterisation. The analysis revealed the presence of novel organisms which were renamed as Acetobacter pasteurianus strain YVB24 and Acetobacter pasteurianus strain AJN29, after characterisation of the strains they were deposited in Gene bank with the following accession numbers "KX831391" and "KX831390" respectively. The results suggest the positive isolation of indigenous acidic acid bacteria from the Western Ghats soil sample. This study aims to isolate the acetic acid bacteria found in the Western Ghats Soil and Characterise and study them for the production of the acetic acid. Hence it can be used for future studies.

\section{Introduction}

Acetic acid bacteria (AAB) are gram negative, rod shape and obligate aerobic bacteria with the ability to oxidize ethanol to acetic acid (Kersters et al., 2006; Moryadee and Pathom-Aree, 2008; Maal et al., 2010]. In the past, there were two main genera, Acetobacter and Gluconobacter but at present there are twelve genera which are in the Family Acetobacteraceae, Class Alphaproteobacteria i.e. Acetobacter, Gluconobacter, Gluconacerobacter, Asaia, Kozakia,
Swaminathania, Saccharibacter, Neoasaia, Granulibacter, Tanticharoenia and Ameyamaea (Sengun and Karabiyikli, 2010). One of the key metabolic features of AAB is the conversion of ethanol into acetic acid by two sequential reactions catalyzed by membrane bound alcohol dehydrogenase $(\mathrm{ADH})$ and aldehyde de-hydrogenase (ALDH) enzymes (Matsushita et al., 1994). It remain important process as many countries law stipulate that food grade vinegar must come from biological origin (fermentation). 
Therefore, optimization of biological process for acetic acid production is one of the most important areas of industrial research. For industrial production, there are several species of Acetobacter that can be described as the main vinegar producer such as A. aceti, A. pateurianus, A. peroxydans, A. orleaniensis, A. lovaniensis, A. estuniensis, A. malorum, A. cerevisiae and A. oeni. Therefore, Acetobacter is usually used in the production of vinegar from ethanol through acetaldehyde by consumed oxygen (Kondo and Kondo, 1996). The oxygen requirement for Acetobacter conversion makes the processes energy intensive. Carbon source used plays important role for bacterial growth and acetic acid production. It has been reported that, sugars such as: arabinose, xylose, ribose, glucose, galactose, mannose, melibiose, and trehalose can be fermented by most of the Acetobacter strains [Kadere $\mathrm{T} T$ et.al 2008]. $\mathrm{AAB}$ are easily available in nature as they display high resistance to acidity, some of the sources are vinegar, fruits, honey, sugarcane juice, soil and water [Yamada Y et.al 1999]. An attempt has always been made to isolate high acid tolerance, thermophilic bacteria. Hence in this study an effort is made to isolate indigenous acetic acid bacteria of Western Ghats to determine its properties. The identification of the bacteria was carried out by $16 \mathrm{~s}$ rRNA analysis technique.

\section{Material and Methods}

The soil samples were collected in and around the Belgaum and Khanapur regions of the Western Ghats. The soil samples were at a depth of $15-20 \mathrm{~cm}$ from the surface. A total of fourteen different soil samples were collected for the isolation of the target bacteria.

\section{Primary Screening}

About $1 \mathrm{gm}$ of the fine soil sample was dissolved in $9 \mathrm{ml}$ of distil water for serial dilution. The $10^{-4}, 10^{-5}, 10^{-6}$ dilutions were inoculated on the GYC media (10\% glucose, $1.0 \%$ yeast extract, $2.0 \%$ calcium carbonate and $1.5 \%$ agar, $\mathrm{pH}-6.5$ ). The similar procedure was carried out for all the soil samples. All the plates were incubated at $32^{\circ} \mathrm{C}$ for not less than 72 hours under aerobic condition. The colonies showing slightly yellowish colour and yellow colour showing halo around the colonies having high probability of Acetobacter were separately subcultured in the GYC medium. The Carr medium supplemented with bromocresol blue $(100 \mathrm{mg} / \mathrm{ml})$ was used to confirm the same. The same media was also used to differentiate the Acetobacter form other species as the Acetobacter turns the media colour to yellow and then to green.

\section{Acetic acid production}

The obtained colonies were cultured in Yeast Glucose ethanol acetic acid medium with different concentration of ethanol for acid production. The media was kept under constant aeration and agitation at temperature of $35^{\circ} \mathrm{C}$ and the sampling was done at intervals of 24 hours. The maximum acid was produced with different concentration of components in the media.

\section{Estimation of acetic acid production in the medium}

The amount of acid present was determined by titration method as given by BeheshtiMaal and Shafiee (2010). About $5 \mathrm{ml}$ of the culture medium was added with $20 \mathrm{ml}$ of distilled water along with phenolphthalein as indicator. The solution was titrated against $0.5 \mathrm{~N}$ sodium hydroxide $(\mathrm{NaOH})$.

The amount of sodium hydroxide consumed is used to determine the acetic acid in the medium. The acetic acid produced in $100 \mathrm{ml}$ of media was calculated using: 
Acetic acid $(\mathrm{g} / \mathrm{ml})=$ Volume of $\mathrm{NaOH}$ consumed in titration $\times 0.03 \times 20$

\section{Identification of acetobacter species}

\section{Morphological and biochemical characterisation}

The positive colonies were further inoculated on nutrient agar and were grown. These were analysed by Gram staining and Biochemical tests like Oxidase test, IMVIC, Mobility test and Nitrate reduction tests were performed. The nitrate reduction test was performed using nitrate peptone water (peptone - 10g; $\mathrm{KNO}_{3}-2 \mathrm{~g}, \mathrm{pH}-7.0$ per litre of distil water) (Franke et al., 1999). Additionally the motility test was carried out by Hanging drop and soft agar stabbing (Tube method) methods.

\section{Identification by 16s rRNA analysis and PCR amplification}

Among total of 20 isolates only 2 were considered for identification. The 16s rRNA was carried after the biochemical tests for the confirmation of the isolates. The bacterial isolates were grown in GYC medium for 2-5 days at $32^{\circ} \mathrm{C}$ and the chromosomal DNA was isolated using method described by Stephan $e t$ al., (1998). The PCR amplification of the isolated DNA was carried out using the following primers:

16sF (Forward primer) AGAGTTTGATCCTGGCTCAG- 3'

\section{6sREV (Reverse Primer) 5'- ACGGCTACCTTGTTACGACCT - 3'}

A total of $25 \mu$ of the PCR mixture was prepared by addition of the components as given in table 2 . The PCR was carried with the following parameters: Initial denaturation at $94^{\circ} \mathrm{C}$ for 120 seconds followed by the Denaturation at $94^{\circ} \mathrm{C}$ for 30 seconds, Annealing was done at $55^{\circ} \mathrm{C}$ for 30 seconds.
Elongation was done at $72^{\circ} \mathrm{C}$ for 90 seconds with the final elongation being done at $72^{\circ} \mathrm{C}$ for 600 seconds. The lid temperature was maintained at $105^{\circ} \mathrm{C}$ to prevent any loss of the reaction mixture. The obtained PCR products were purified and observed in 1\% agarose gel.

\section{Restriction analysis and phylogenic tree construction}

The restriction analysis of the PCR products was carried out using the EcoRI and EcoRII enzymes. The digested fragments were detected on $1 \%$ agarose gel and were compared to standard DNA ladder. The digestion was carried out for about $3 \mathrm{hrs}$ at $35^{\circ} \mathrm{C}$ as recommended by the manufacturer. The isolated sequences were subjected to phylogenic tree construction.

\section{Results and Discussion}

The objective of the study was to isolate the indigenous acetic acid bacteria present in Western Ghats region. Hence for this different types of soil samples were targeted for isolation. Out of the total isolates obtained 17 isolates (Yellow and pale yellow coloies) were suspected as acetobacter species, only two isolates showing distinct clear zones on GYC media were selected for further analysis. The Carr medium supplemented with bromocresol blue $(100 \mathrm{mg} / \mathrm{ml})$ was used to confirm the production of acid by the bacteria (Figure 1). The same media was also used to differentiate the acetobacter form other species as the acetobacter turns the media colour to yellow and then to green (Figure 2).

\section{Morphological and biochemical characterisation}

Acetobacter pasteurianus a member of alphaproteobacteria class is gram negative obligatory aerobic organism with an ability to oxidise alcohol and sugars into corresponding organic acids, using alcohol dehydrogenase 
enzyme. The examination of the primary screened colonies by gram staining reveled them to be gram negative rod shaped cells arranged in chain formation as shown in figure 3 (a \& b). From motility test it was confirmed that organisms were motile in nature and strictly aerobic as shown in figure $3(\mathrm{c})$. They showed positive growth at $\mathrm{pH}$ range of 5.0-6.0. The two obtained positive selected isolates were subjected to biochemical tests such as Oxidase test, Gelatin hydrolysis, IMVIC tests and nitrate reduction test.

The isolates displayed negative results for oxidase, gelatinase and Indole while nitrate, catalase and MRVP tests revealed positive results. Hence the preliminary analysis of the isolates based on table 3 and the characterisation data of species as in table 1, can indicate the isolate as Acetobacter pasteurianus. Hence the 16s rRNA technique was further employed to confirm the isolate.

\section{PCR amplification and identification by 16s rRNA technique}

Out of 17 total isolates of acetobacter;two isolates were selected for the molecular identification technique based on the purity of the isolates and biochemical test results. Some amount of isolated DNA subsequently run in $1 \%$ agarose gel (Figure 4) for confirmation while purified DNA was used for PCR amplification by specific set of primers and obtained product was visualised under $1 \%$ agarose gel (Figure 5). The sample was sent to Chromous Biotech Pvt. Ltd for commercial sequencing.

The obtained sequences were 1473bp (AJN29) and 1454bp (YVB24) in length. Analysis of obtained sequences by using BLAST (similarity search program) at NCBI revealed divergent strains of $A$. pasteurianus (Gene bank accession numbers "KX831391" and "KX831390").

Fig.1 Colonies obtained on Carr medium supplemented with bromocresol blue

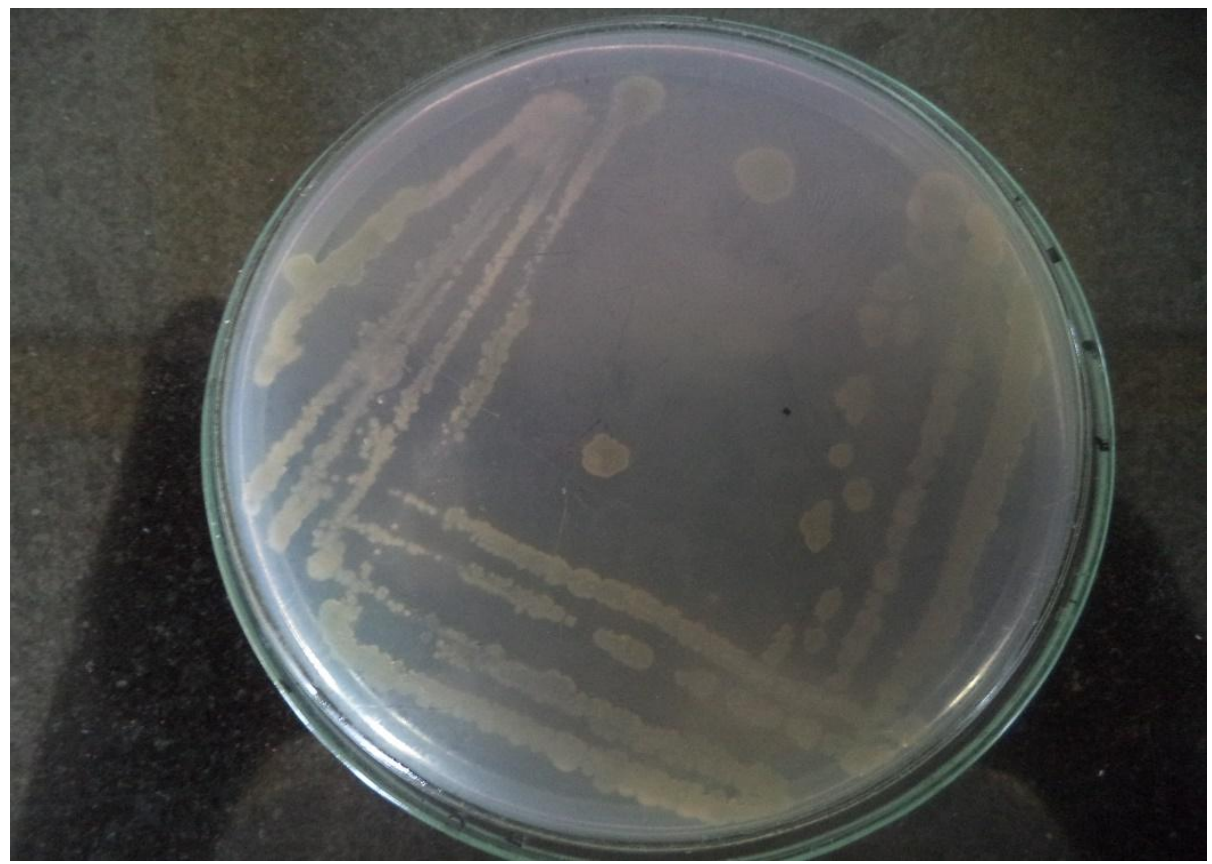


Fig.2 Yellow colonies obtained on the Carr medium supplemented with bromocresol blue confirming the isolates

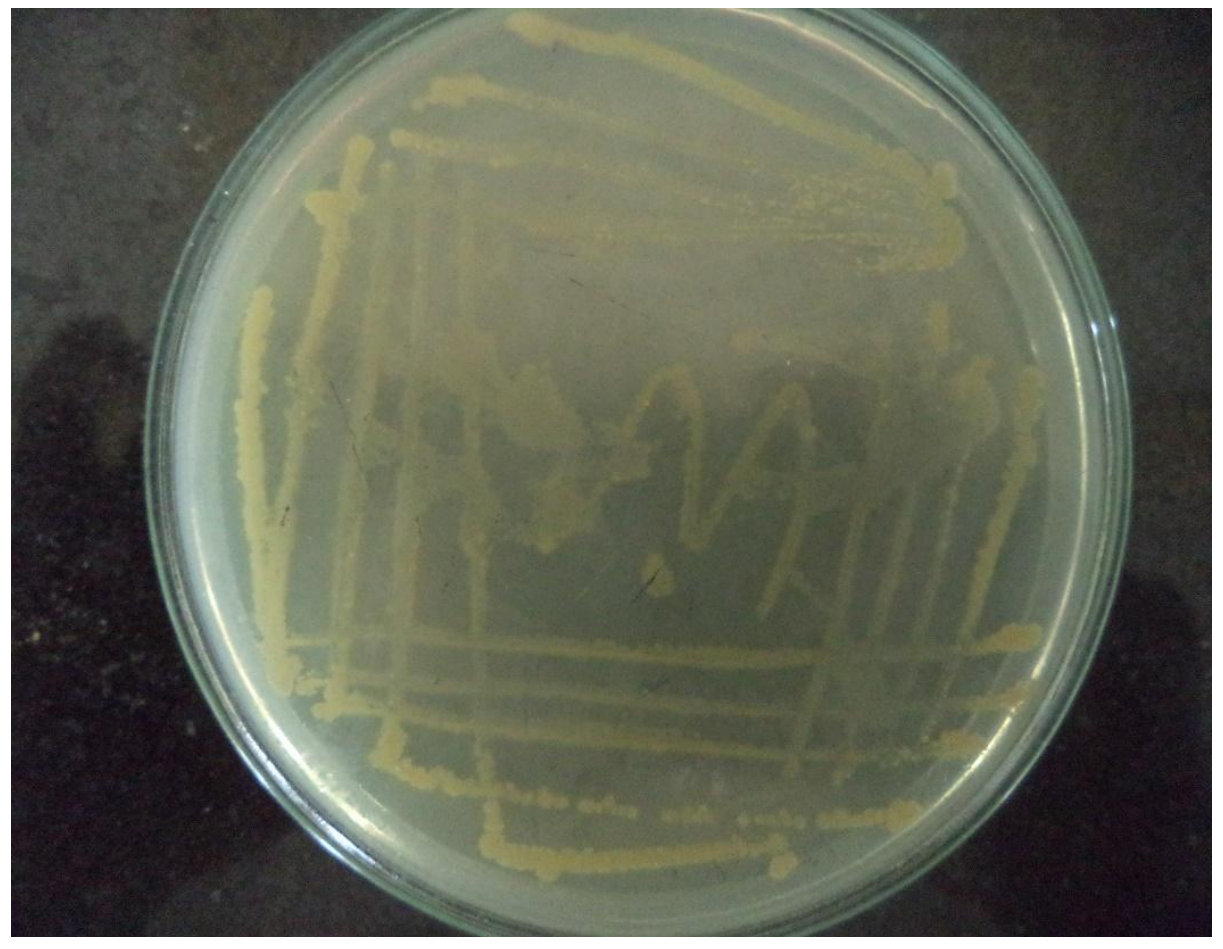

Fig.3 (a\&b) Gram negative, rod shaped arranged in chain

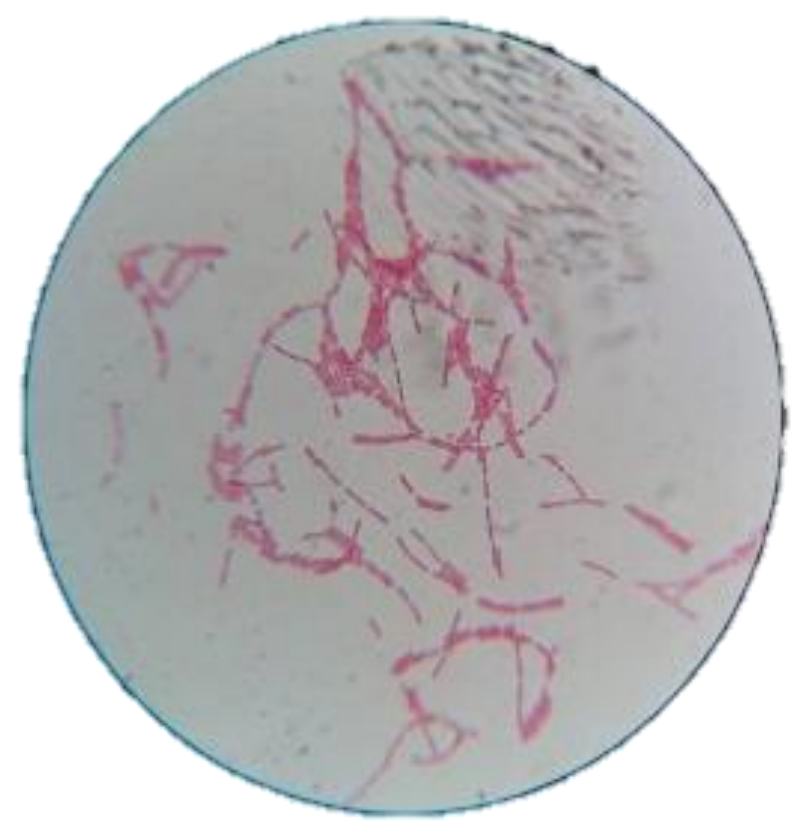

Figure 3: (a) 


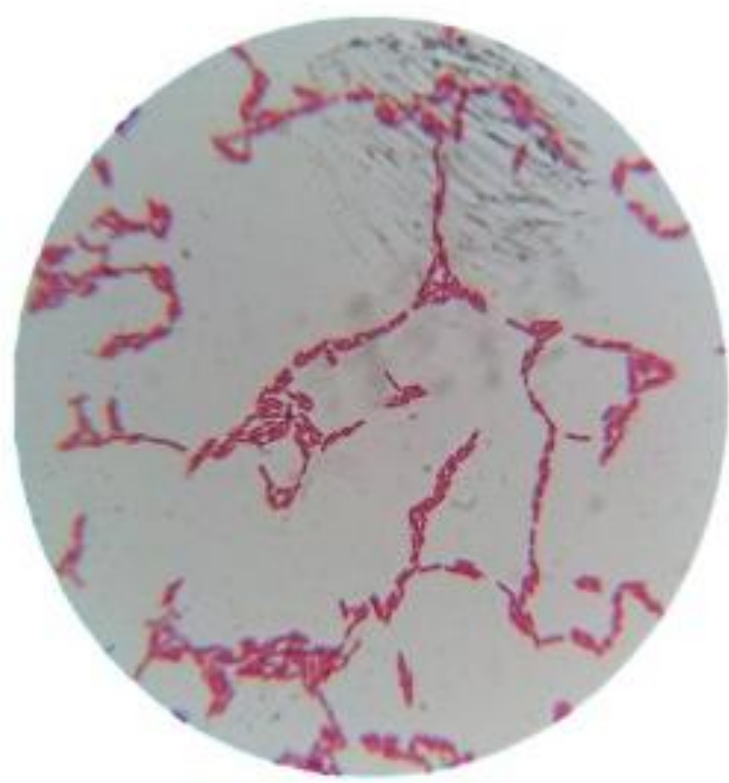

Figure: 3(b)

Fig.3 (c) Motility test (tube method)

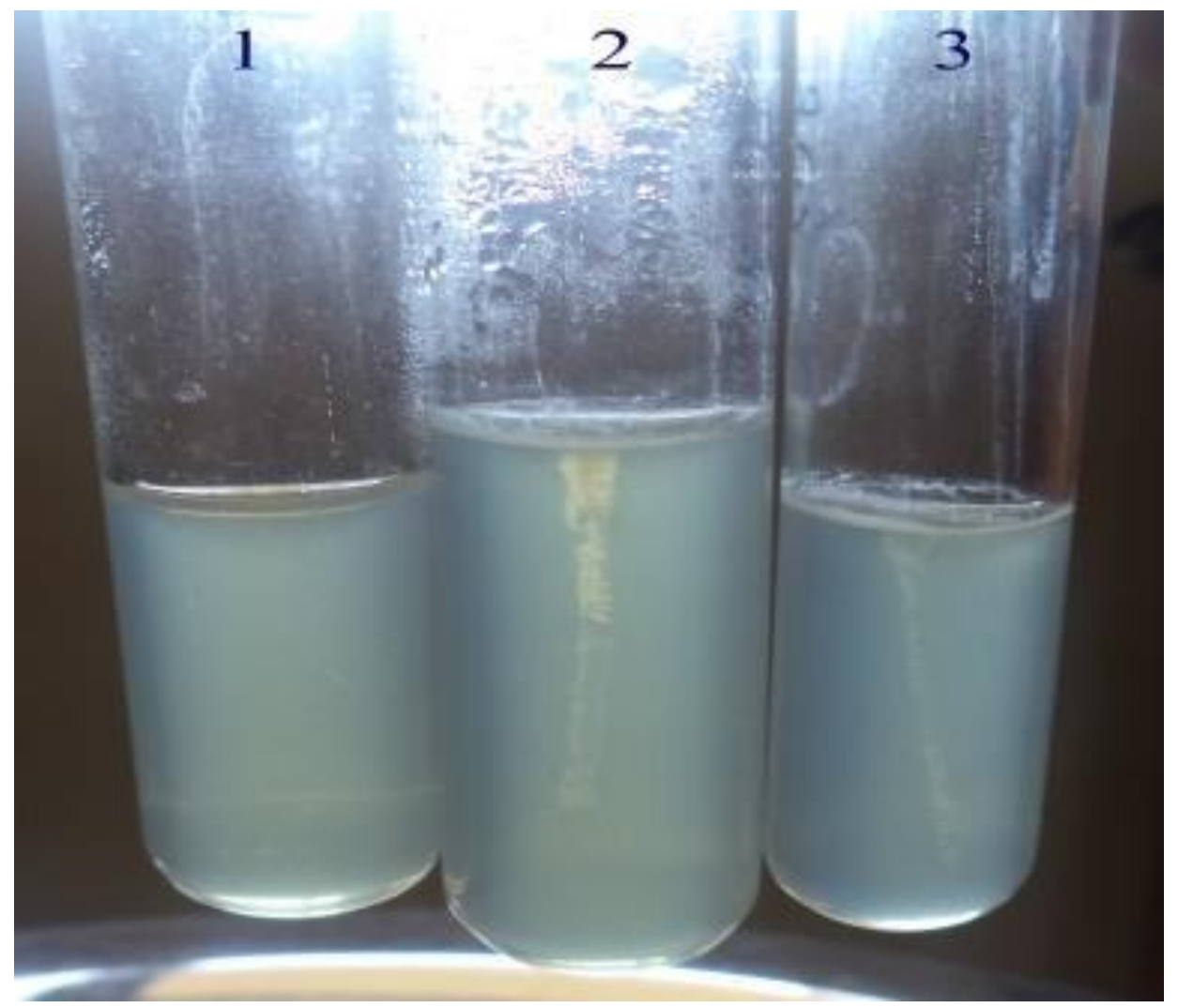


Fig.4 Genomic DNA loaded on 1\% agarose gel. Lane description: 1- strain AJN29, 2- strain YVB24

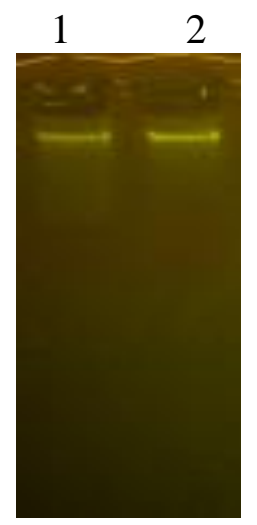

Fig.5 PCR product loaded on 1\% agarose gel. Lane description: 1- Strain AJN29 (1.5 kb), 2 500bp DNA ladder, 3 - Strain YVB24 (1.5kb)

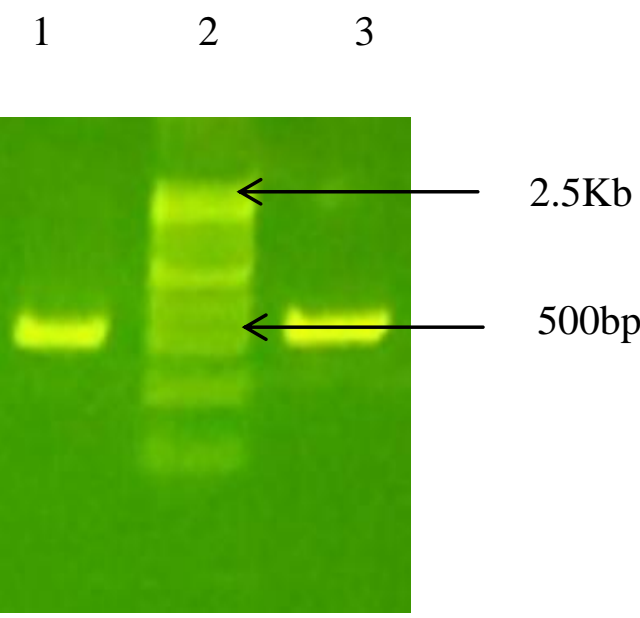

Fig.6(a) Phylogenetic analysis of the sequence YVB24

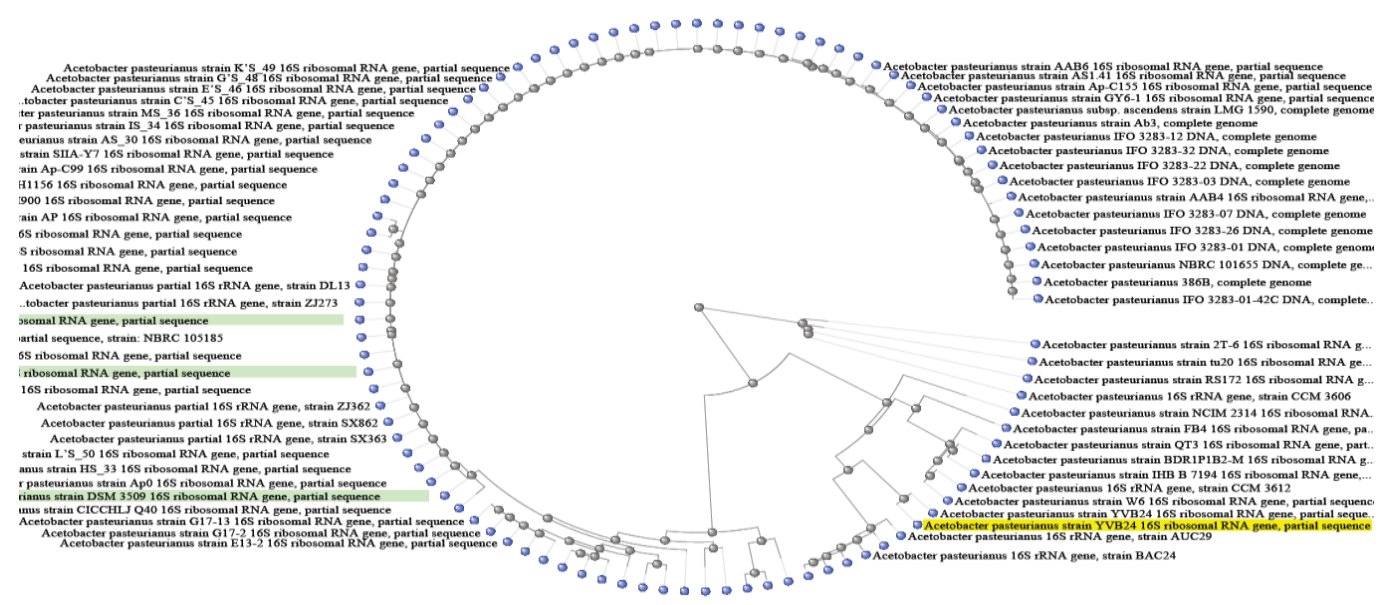


Fig.6(b) Phylogenetic analysis of the sequence AJN29

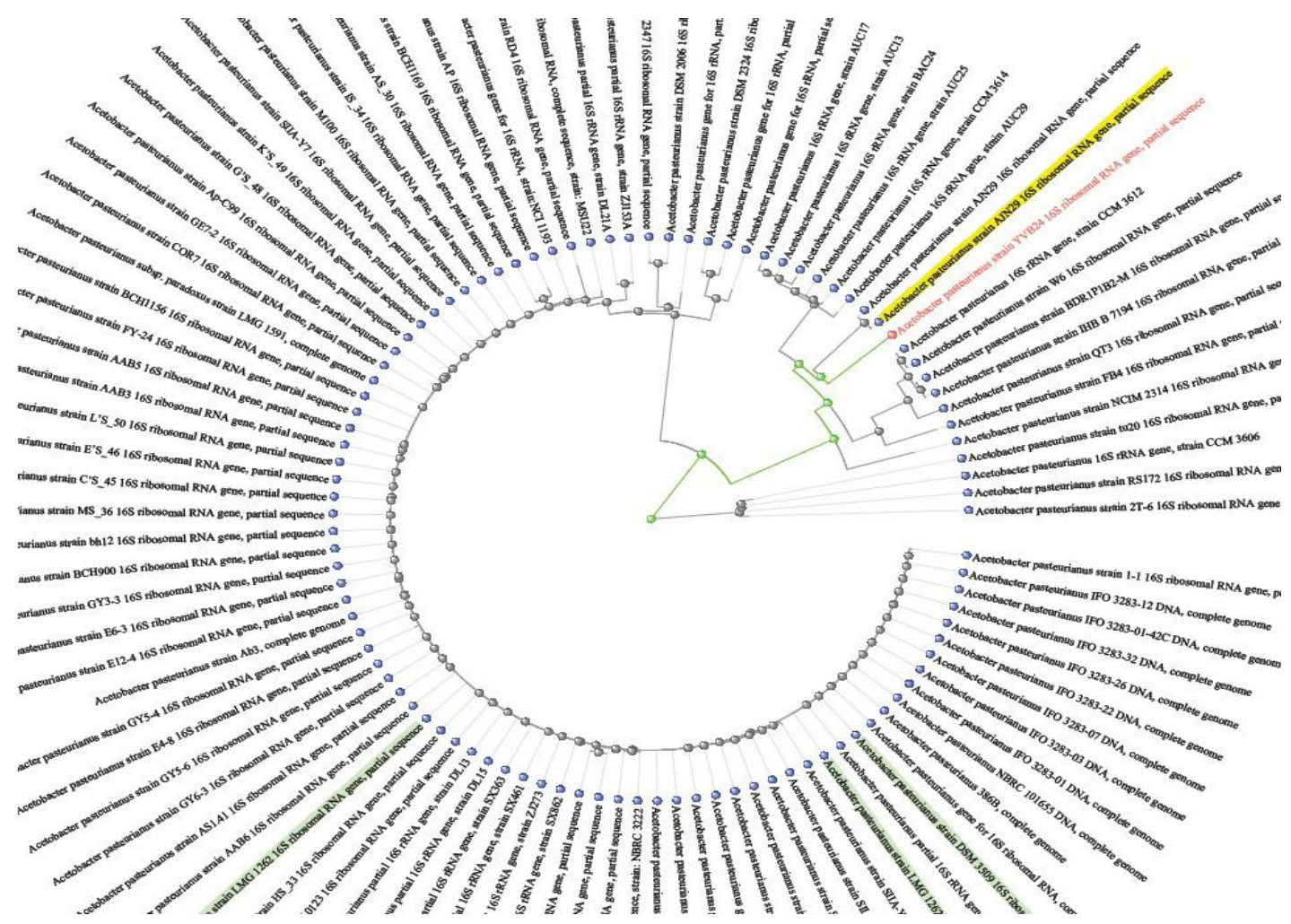

Fig.7 Production of the acetic acid by the isolated strains in YGEA media

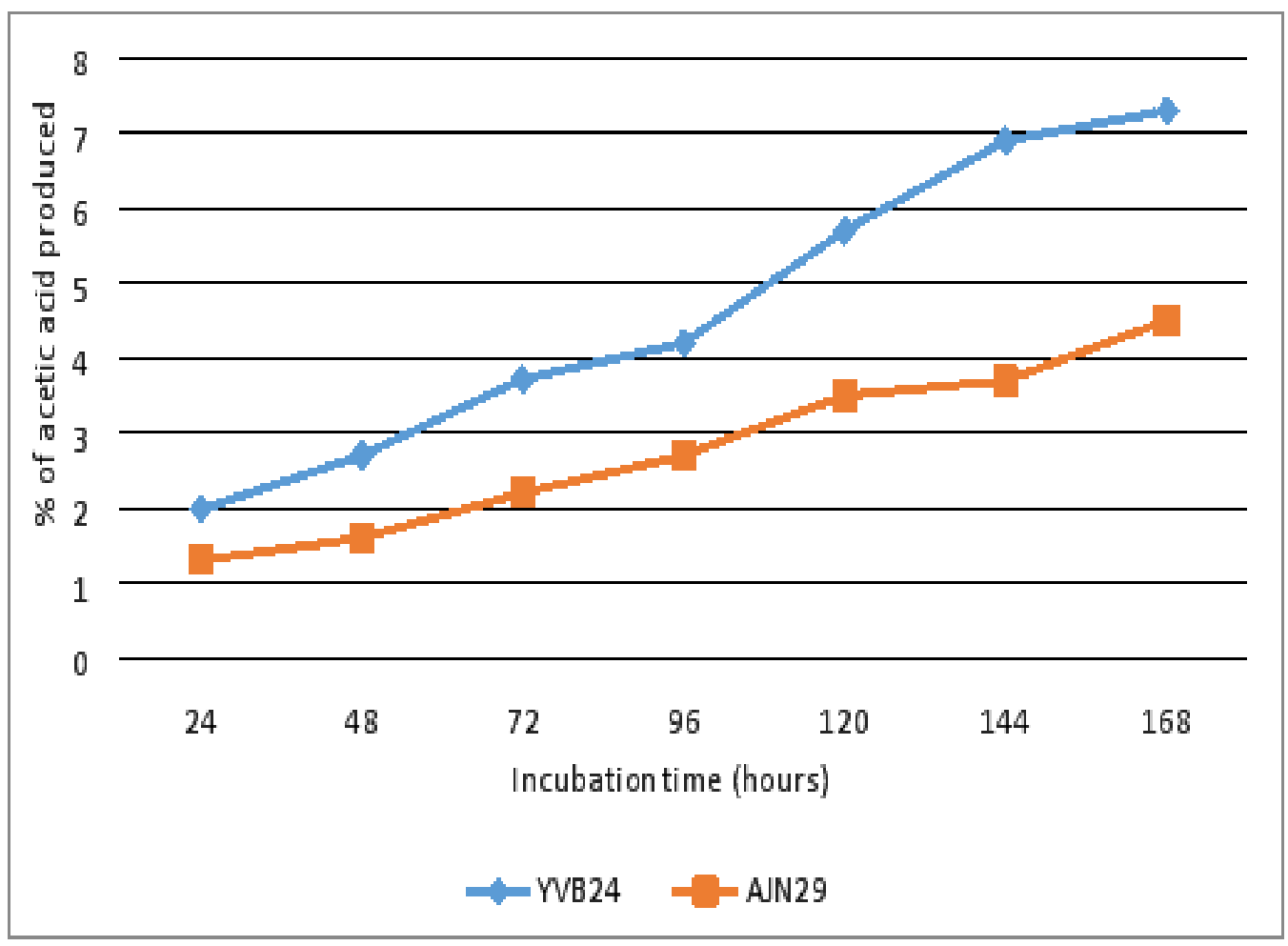


Table.1 Characters of some species of Acetobacter

\begin{tabular}{|c|c|c|c|c|c|c|}
\hline Tests & 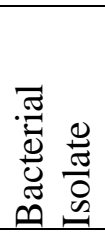 & $\begin{array}{l}\tilde{I} \\
0 \\
0 \\
0 \\
\dot{\pi}\end{array}$ & 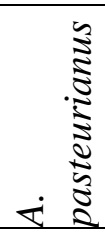 & 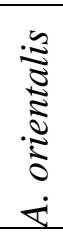 & 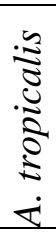 & 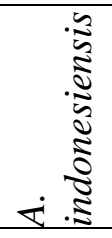 \\
\hline Catalase & & + & + & + & + & + \\
\hline Ketogenesis from glycerol & & + & $\mathrm{V}$ & - & - & - \\
\hline Production of acid from D-glucose & & + & $\mathrm{V}$ & + & + & + \\
\hline Nitrate Reduction & & - & + & - & - & V \\
\hline
\end{tabular}

Symbols: (+) $-90 \%$ or more strains positive result, (-) $90 \%$ or more strains negative result, $\mathrm{V}-10-80 \%$ positive strains.

Table. 2 Components and there quantities involved in the PCR reaction

\begin{tabular}{|l|l|}
\hline Components & Volume $(\mu \mathrm{l})$ \\
\hline Taq Polymerase (Ready mix) & 12.5 \\
\hline Forward Primer & 0.5 \\
\hline Reverse Primer & 0.5 \\
\hline Template DNA & 3 \\
\hline PCR Water & 8.5 \\
\hline
\end{tabular}

Table. 3 Bio-chemical characters of the obtained acetobacter species,

\begin{tabular}{|c|c|c|c|c|c|c|}
\hline \multicolumn{7}{|c|}{ Symbols: + (positive), - (negative) } \\
\hline Bacterial isolates & $\stackrel{\tilde{\tilde{U}}}{\mathscr{\theta}}$ & $\begin{array}{l}\frac{8}{\tilde{\sigma}} \\
\frac{\pi}{\tilde{J}} \\
\tilde{U}\end{array}$ & 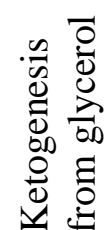 & 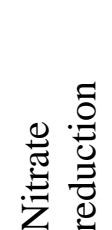 & $\frac{\Xi}{\frac{\Xi}{0}}$ & $\sum_{z}^{f}$ \\
\hline YVB24 & & + & + & + & - & + \\
\hline AJN29 & & + & + & + & - & + \\
\hline
\end{tabular}

\section{Restriction analysis and phylogenetic analysis}

The software analysis of the obtained sequence suggested the presence of the restriction sites on the gene; hence it was subjected to restriction digestion by the following enzymes EcoRI and EcoRII. The digestion led to formation of $1031+234+102+37$ and 1454bp (KX831391); $1035+233+106+99$ and 1473 (KX831390) fragments. The phylogenetic analysis of the strains (Figure 6 a \& b) was carried out using ClustalW software (www.ebi.ac.uk) to determine similarity and close relationship to isolate. The phylogenetic tree analysis revealed that sequence was closely related to acetobacter species.

\section{Acid production}

The optimal temperature for the growth of the media was found to be $31^{0} \mathrm{C}$ at shaking speed of 130 rpm; medium in which maximum acid production observed was composed of $2 \%$ glucose, $2 \%$ yeast extract, $3 \%$ ethanol and 3\% acetic acid (Figure 7). The maximum acid produced was $7.3 \%$ for strain YVB24 while strain AJN29 had $4.5 \%$ of acid. The acetic acid bacteria are well known in the production of alcohol and acetic acid from various types of carbon sources. Oxidation is one of the major problems in producing acetic acid. Due lack of glucose or ethanol concentration acetobacter or gluconobacter can further oxidize acetic acid to $\mathrm{CO}_{2}$ and $\mathrm{H}_{2} \mathrm{O}$. Changes in the strain physiology 
and temperature, lack of alcoholic substrate are some of the factors contributing for oxidation (Sokollek S J et.al 1998). In present study the isolates were grown in the GYC media. The further screening was carried out by biochemical characterization and molecular analysis.

In addition to their capacity to oxidise ethanol to organic acids, Acetobacter and Gluconobacter species can oxidise the acids further into $\mathrm{CO}_{2}$ and $\mathrm{H}_{2} \mathrm{O}$ by the acetate over oxidation process. This process is carried out by bacteria tricarboxylic acid cycle (TCA) in presence of high dissolved oxygen and absence of ethanol in the medium. Unlike their counterparts the Gluconobacter is not able to oxidise the acids as they have non-functional $\alpha$ ketoglutarate and succinate dehydrogenase of TCA cycle (Sakurai et al., 2013). Hence the presence of the ethanol in the medium represses the activity of TCA enzyme cycles in Acetobacter species (Hiroyuki Arai, 2012). Therefore the production of the acid in the medium can be seen in form of clearing of opacity of medium as described by Frateur et al., (1950) or the colour change of bromocresol green indicator as described by Swings et al., (1992) confirms that the isolate is acetobacter species. The amplified PCR products of isolates were roughly 1500bp (Figure 3). This fragments were sequenced (1454bp and 1473bp) and aligned using BLAST tool and similarities were found with Acetobacter pasteurianus. The phenotypic characterisations of the $\mathrm{AAB}$ were not reliable and time consuming in nature. Hence most of the authors reported molecular procedures based on restriction fragment analysis like that of RAPD, RFLP, 16s rRNA as appropriate techniques for characterisation of microorganisms (Poblet et al., 2000; González et al., 2006). Hence the identity of the isolates were confirmed by the 16s rRNA method, as Acetobacter pasteurianus. The temperature also plays an important parameter as deviation in optimal temperature of the process leads to inactivation of the enzymes, which in turn affects microbial action. In this case the organism is affected by toxic nature of acetic acid (De Ory, 1998). While several authors have reported isolation of thermophilic strains of $\mathrm{AAB}$ for industrial fermentation (Moonmangmee, 2000), in present study a temperature of $35^{\circ} \mathrm{C}$ was used growth temperature. Hence in summary it can be reported that two distinct strains of Acetobacter pasteurianus were isolated from the Western Ghats region (Gene bank accession numbers "KX831391" and "KX831390") and confirmed at molecular level by 16s rRNA method. These strains can be further utilized and developed for fermentation process of acetic acid.

\section{Acknowledgements}

The above work was carried out at Department of Biotechnology, Basaveshwar Engineering College, Bagalkot. We thank the department of Biotechnology for letting us carryout this project.

\section{References}

Beheshti-Maal, K., and Shafiee R 2010. Isolation and Characterization of an Acetobacter Strain from Iranian WhiteRed Cherry as a Potential Strain for Cherry Vinegar Production in Microbial Biotechnology. Asian Journal of Biotechnology, 2: 53-59.

DeOry, I., Romero L E, Cantero D 1998. Modeling the kinetics of growth of Acetobacter aceti in discontinuous culture: Influence of the temperature of operation. Appl. Microbiol. Biotechnol., 49:189-193.

Franke, I.H., Fegan M, Hayward C, Leonard G, Sly L I 1999. Description of Gluconacetobactersacchari sp. Nov a new species of acetic acid bacterium isolated from the leaf sheath of sugar cane and from the pink sugar-cane mealy bug. Int $J$ Syst Bacteriol., 49:1681-1693.

Frateur, J., Essaisur la systematique des acetobacters 1950. 13. Cellule.53:392.

González, A., Guillamón J M, Mas A, Poblet M 2006. Application of molecular methods for routine identification of acetic acid 
bacteria. Int J Food Microbiol, 108(1): 141-146. doi: 10.1016/ j.ijfoodmicro. 2005.10.025.

Hiroyuki Arai, 2012. Analysis of energy metabolism in acetic acid bacteria during oxidative fermentation. Department of Biotechnology, the University of Tokyo.

Kadere, T.T., Miyamoto $\mathrm{T}$, Oniang $\mathrm{R} \mathrm{K}$, Kutima P M and Njoroge S M. 2008. Afr. J. Biotechnol. 7, 2963-2971.

Kersters, K., Lisdiyanti, P., Komagata. K. and Swings. J. 2006. The Family Acetobactaceae: The Genera Acetobacter, Acidomonas, Asaia, Gluconacetobacter, Gluconobacter, and Kozakia. Prokaryotes. 5: 163-200. Food and Applied Bioscience Journal, 3 (1): 30-38.

Kondo, T., and Kondo M 1996. J. of Ferment. Bioeng., 81: 42-46.

Maal, K.B., Shafiei R, and Kabir N 2010. Production of Apricot Vinegar Using an Isolated Acetobacter Strain from Iranian Apricot. World Academy of Science, Engineering and Technology. 71: 177180.

Matsushita, K., Toyama H, Adachi O 1994. Respiratory chains and bioenergetics of acetic acid bacteria. Adv Microb Physiol. 36:247-301.

Moonmangmee, D., Adachi O, Ano Y, Shinagawa E, Toyama H, Theeragool G, Lotong N, Matsushita K 2000. Isolation and Characterization of Thermotolerant Gluconobacter Strains Catalyzing Oxidative Fermentation at Higher Temperatures. Biosci Biotechnol Biochem, 64:2306-2315.

Moryadee, A., and Pathom-Aree W 2008. Isolation of Thermotolerant Acetic Acid Bacteria from Fruits for Vinegar Production. Journal of Microbiology. 3(3): 209-212.
Poblet, M., Rozes N, Guillamon J M, Mas A 2000. Identification of acetic acid bacteria by restriction fragment length polymorphism analysis of a PCRamplified fragment of the gene coding for $16 \mathrm{~S}$ rRNA. Journal of Applied Microbiology. Pp. 31-34.

Sakurai, K., Yamazaki, S., Ishii, M., Igarashi, Y., and Arai, H. 2013. Role of the glyoxylate pathway in acetic acid production by Acetobacteraceti. J. Biosci. Bioeng. 115.

Sharafi, S.M., Rasooli I, Beheshti-Maal K 2010. Isolation, characterization and optimization of indigenous acetic acid bacteria and evaluation of their preservation methods. Iranian Journal of Microbiology, 2: 38-45.

Sokollek, S.J., Hertel C, Hammes W P 1998. Description of Acetobacter oboediens sp. nov. and Acetobacter pomorum sp. nov. two new species isolated from industrial vinegar fermentations. Int $J$ Syst Bacteriol. 48: 935-940.

Stephan, J., Sokollek, Christian HerteI and Walter P. Hammes 1998. International Journal of Systematic Bacteriology, 48:935-940.

Swings, J., 1992. The genera Acetobacter and Gluconobacterin: The Prokaryotes. $A$ Handbook on the Biology of Bacteria: Ecophysiology, Isolation, Identiccation, Applications. New York, SpringerVerlag, 3: 2268-2286.

Yamada, Y., Hosono R, Lisdyanti P, Widyastuti Y, Sa4. Ono S, Uchimura T, Komagata K 1999. Identification of acetic acid bacteria isolated from Indonesian sources, especially of isolates classified in the genus Gluconobacter. J Gen ApplMicrobiol., 45: 23-28.

\section{How to cite this article:}

Anurag Bellankimath, Ajay Katti, V.B. Hemalata and Bharati S. Meti. 2017. Isolation and Characterization of the Indigenous Acetic Acid Bacteria from Western Ghats Soil Samples. Int.J.Curr.Microbiol.App.Sci. 6(9): 1255-1265. doi: https://doi.org/10.20546/ijcmas.2017.609.151 